\title{
Efficacy of Augmented Reality in Medical Education
}

\author{
Venkata Naga Satya Surendra Chimakurthi \\ Technical Manager - Projects, EBA - Ventures - Digital Asset Management (DAM), Cognizant Technology Solutions, Dallas, USA \\ *Email for Correspondence: chvnssurendra@gmail.com
}

\begin{abstract}
Augmented reality has had a great development in various fields such as education, architecture, marketing, and tourism. However, there is another field in which it can be really useful, so much so that it can save lives: medicine. In this article, there is a detailed explanation of how augmented reality proved itself effective in medical education. The hospitals and health centers increasingly have more modern equipment that allows accurate diagnoses and effective treatments put up. This is the case of advances such as X-rays, magnetic resonances, ultrasound treatments, or computed tomography, among many others. The uses of augmented reality in medicine are very varied, although it is still a technology in an early stage of development. It is very likely that, in a short time, the applications of AR in the health sector will multiply. Moreover, it might be used in severe rather than typical or random criteria.
\end{abstract}

Key words: Augmented Reality, Medical Education, Technology

This article is is licensed under a Creative Commons Attribution-NonCommercial 4.0 International License.

Attribution-NonCommercial (CC BY-NC) license lets others remix, tweak, and build upon work non-commercially, and although the new works must also

acknowledge and be non-commercial.

\section{INTRODUCTION}

Few of us look forward to a visit to the doctor or hospital, and far fewer dream of spending the twilight of our lives in a medical center. What if new generation medical technologies could make these ordeals less difficult? Perhaps then the inimitable smell of hospital antiseptic wouldn't repel us so much.

The augmented reality is something tangible in the world of health and medicine. This technology consists of improving the real-world environment with virtual elements that complete it by providing complementary information. Augmented reality is unique because users do not lose contact with the real context in which they operate, and it puts information at our fingertips almost immediately.

In any case, this is what many companies are hoping for, exploring the various applications of $3 \mathrm{D}$ technologies, augmented reality and virtual reality in the health sector. In this sector, innovations affect two categories of people: medical staff and patients. And these technologies are no exception to the rule. For doctors and medical staff, they promise real leaps forward in training and education. On the patient side, they constitute an increase in involvement and an improvement in care, rehabilitation, and comfort (Barsom et al., 2016).

\section{LITERATURE REVIEW}

The source of the problem in the educational system of several Latin American countries lies in the lack of innovative tools that promote an optimal way to capture the attention of students and the interest that each subject requires, since they are overshadowed by being monotonous due to the conventional way in which they are taught (Vera et al., 2014). That is why between 2017 and 2018, in Argentina and Mexico, a Research and Development Project (PID) was developed that managed to make anatomical and physiological prototypes that use augmented reality as a central axis, this helped increase motivation towards the development of cognitive skills and interest in the development of the modules (Chimakurthi, 2017a). Another case of success occurred in 2016, when the former National Secretary for Information and Communication Technologies (SENATIC, now MITIC) financed four Startups, among them, Increnta 
SA, the purpose of which is to apply AR in various fields of application (Chimakurthi, 2017b). This was enough to draw the attention of multiple national and international companies that began to apply augmented reality, both in their internal practices and with the relationship and interaction with their clients (Williams \& Scott, 2019). This research contributed to complement the traditional way of teaching, which stood out in increasing the motivation of students to learn in a different way than usual. The incorporation of these technologies can generate great benefits to society and shows that traditional education can evolve towards a field of integration for technological tools and in this way achieve enhance knowledge and generate better professionals (Barteit et al., 2019).

\section{MetHodology}

Augmented reality (AR) currently represents a powerful tool that allows virtual elements and graphic information to be superimposed on our vision of reality. It has shown its versatility in a wide field of applications in different areas of knowledge. Augmented reality is one of the few exponential technologies that are growing rapidly, shaping big industries and all aspects of our lives. Absolutely all of them: from the way we watch movies and TV or move around town, to the way we interact with our environment, including health care.

\section{Efficacy of Augmented Reality in Medical}

With AR it is possible to identify and locate objects in our environment, obtain and store specific information about said object, organize and analyze digital information to evaluate its purpose and relevance.

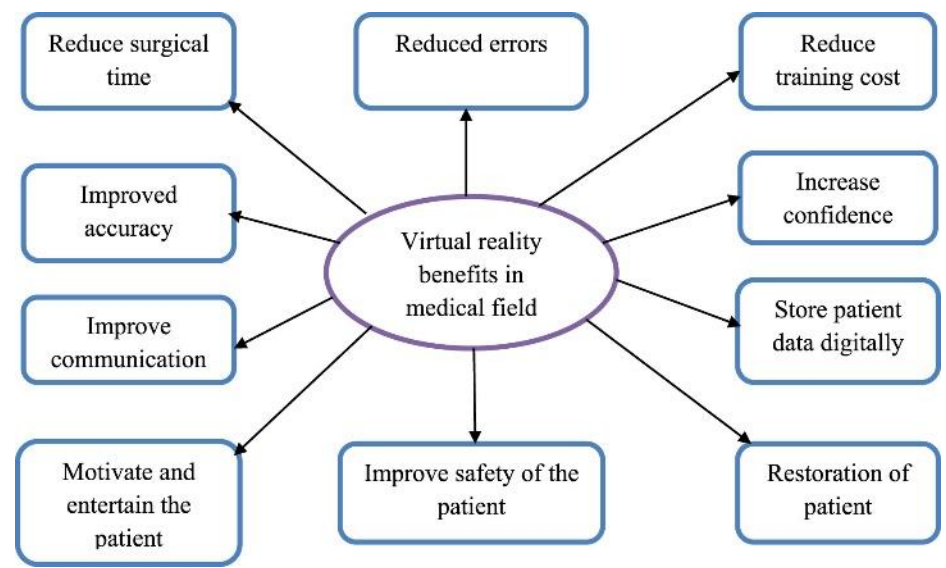

Figure 1: Virtual reality applications toward medical field

As studies by medical imaging pioneer Dr. Maki Sugimoto and others have shown, training healthcare workers in 3D imaging is paying off. After all, 3D models are much more practical than illustrations from a textbook because they allow students to move around and explore them exactly as if it were a real body, without the drawbacks of a body real (Williams \& Scott, 2019). Open Simulation is another company that uses 3D technology to democratize medical education and care through the development of a laparoscopic surgery training simulator. Its mission is to train 2.2 million people in the surgical field in order to help the 5 billion human beings who do not have sufficient access to this type of care. According to Yeshwanth Pulijala, director of medical visualization at Open Simulation, "affordability, real-time interaction and 3D visualization are the most valued features of our program."

Medical Augmented Intelligence offers interactive 3D models of the human body, here, for the training of acupuncturists. The student can move their hand around a digital human body in virtual reality and gain access to an x-ray view of the muscles and nerves into which the needles are to be stuck. "It's really hard for students to overcome the conceptual barrier to full understanding," says Sam Jang, Founder and CEO of Medical Augmented Intelligence. Many acupuncture points treat a variety of symptoms depending on the angle and depth. For example, there are three different approaches to ST36 to treat three different symptoms. And each approach requires its own angle and depth" (Hsieh and Lee, 2018).

Augmented reality in 3D medicine facilitates the preparation and development of surgical operations, although it is true that, in this sense, it is still a technology to be developed (Chimakurthi, 2018). Among other advantages, it helps to choose the most convenient technique for the operation and serves as a guide during the process by offering relevant information. It facilitates the visualization of all types of clinical data. It even allows you to project images in real time from ultrasound or tomography. All this results in much more agile and precise analyzes, in addition to reducing the risk when performing surgical interventions. For example, to detect what app means in medicine or what is the same, to know the personal pathological history of a person. 


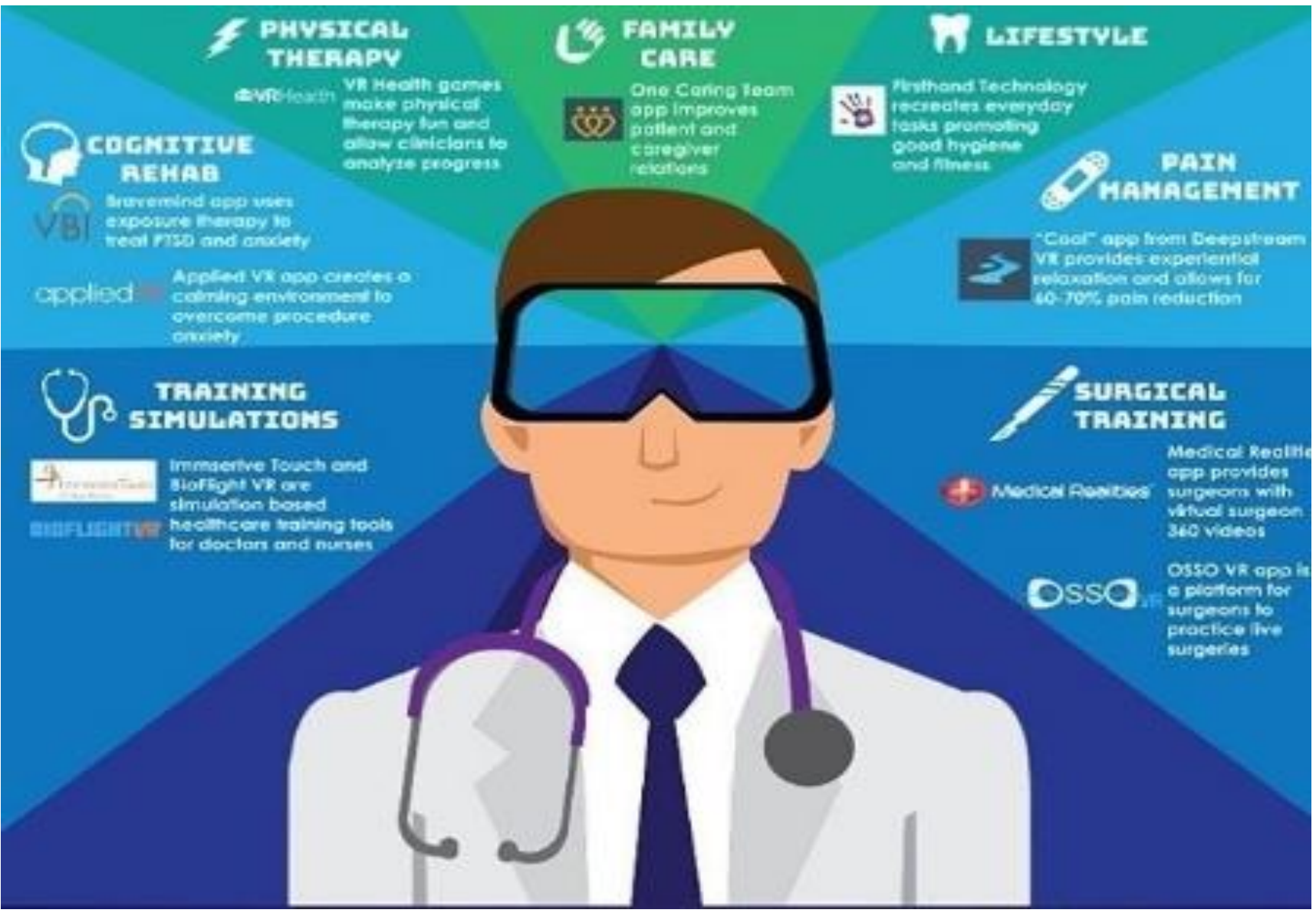

Figure 2: Used in Medical

Viewing images in augmented reality enables the detection of diseases or conditions that might otherwise be difficult to find. For example, tumors that are hidden or in hard-to-reach areas. Augmented reality in medicine can also be applied during rehabilitation processes. It allows you to design and visualize safe virtual situations that can then be applied in reality to improve the patient's recovery (Schijven and Jakimowicz, 2005).

\section{Treatment of Psychological Problems}

Another application of augmented reality in medicine is to serve as a treatment for addictions or phobias. As an example, we can cite an application designed by Phobos Center whose objective is to treat the phobia of spiders through the virtual projection of these insects. It is also used to detect affections in the organs, soft, which are those parts of the body most susceptible to emotional states (Chen et al., 2017).

\section{Training for health professionals}

Without a doubt, one of the main functions of augmented reality in the health sector is and will be the training of professionals. Thanks to it, theoretical knowledge can be practiced in a virtual real setting. In this way, the interaction of the students is increased, their capacities are improved and the costs of material such as mannequins are reduced (Bleakley, 2013).

\section{Augmented Reality in hospitals}

There are examples of the use of augmented reality in medicine all over the world. These are some of the most interesting projects that have been carried out in recent years. But in between here, Thanks to augmented reality apps, doctors can communicate much more easily and visually with patients. For example, showing you where the pain is, where an incision will be made, or showing your vital signs in real time.

\section{The study of the human body}

The Holo Anatomy application allows to visualize the human body in an easy and spectacular way, and to distinguish from the muscles to the smallest veins through a dynamic holographic model. 


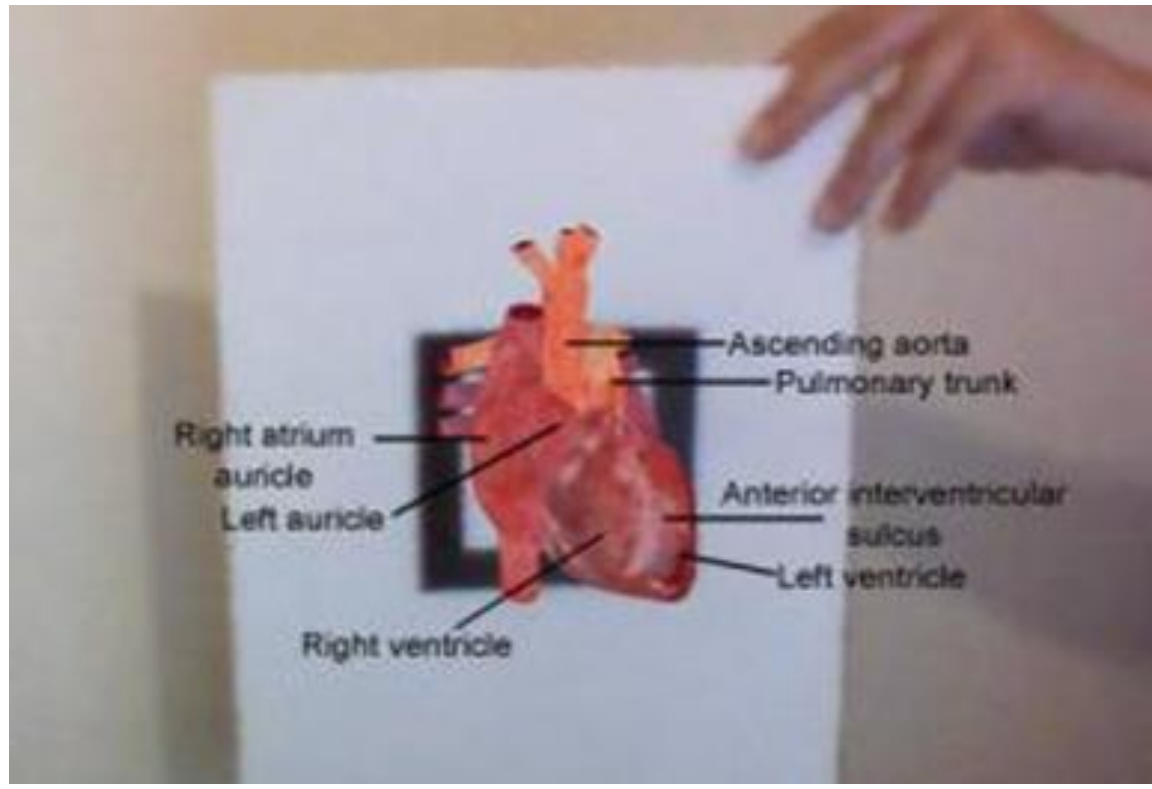

Figure 3: Augmented reality for studying human body

Through this technology, medical students can study in a more dynamic and realistic way the functioning of the human body and the behavior of certain pathologies (Jensen and Konradsen, 2018).

\section{Treatment of autism}

The Brain Power app is designed to teach social skills to children and adults affected by autism. This tool has brain science software and turns Google's augmented reality glasses and other similar devices into a support to carry out educational challenges for people with autism.

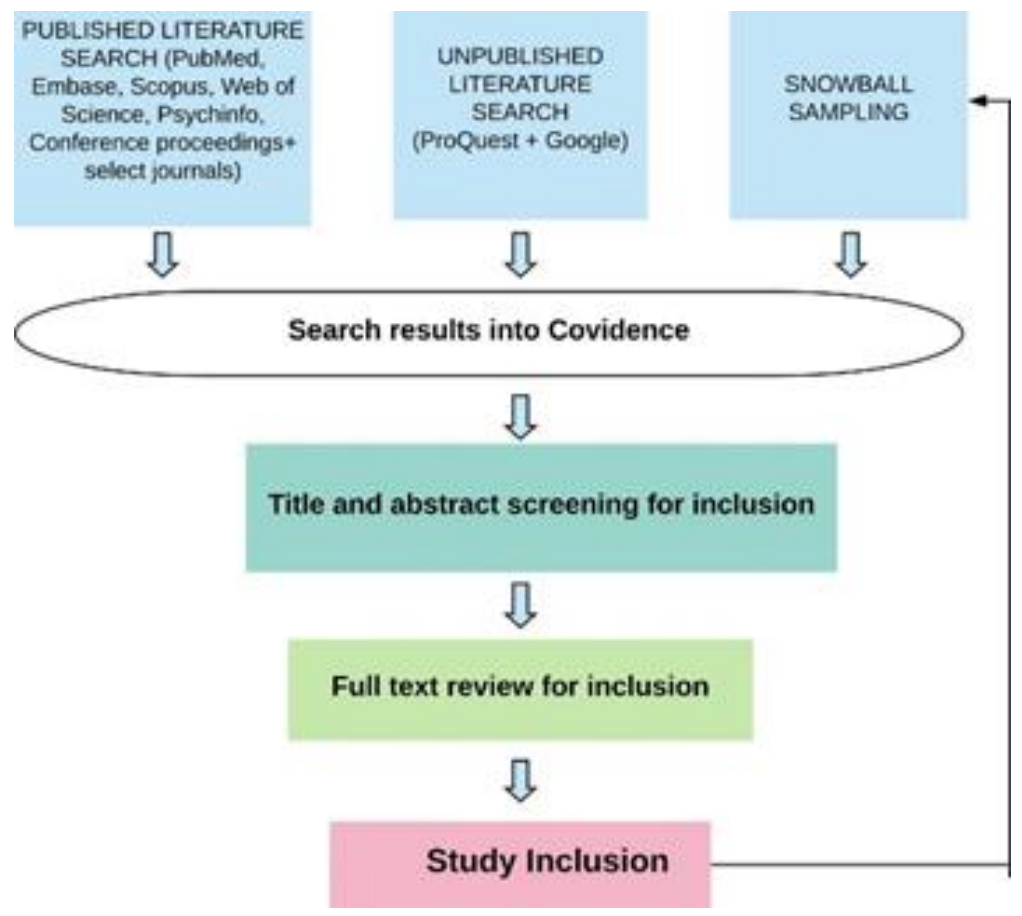

Figure 4: Augmented reality in patient education and health literacy

\section{Applications of augmented reality in the health sector and medical education}

The uses of augmented reality in medicine are very varied, although it is still a technology in an early stage of development. As shown in above fig. 4, it is very likely that, in a short time, the applications of AR in the health sector will multiply. For now, these are some of its main uses (Bretón-López et al., 2010). A medical center at Radboud University in the Netherlands has designed an app called AED4EU that helps find automated external defibrillators 
for urgent cases of heart problems. This tool also allows its users to incorporate the location of new devices so that anyone can project the closest defibrillators through augmented reality. The user only has to open the application, and follow the instructions offered through their mobile phone.

\section{Treatment of phobias and mental disorders}

Augmented reality has made it possible to design immersive experiences to subject patients with mental illness to situations of stress calculated to overcome situations of phobia, panic, anxiety, OCD, etc.

\section{Attendance at surgery}

This technology has become a support tool for surgery that provides greater doses of precision. Devices such as Microsoft's HoloLens manage to superimpose a layer of virtual information on the reality or the vision of organs in 3D and even the vital signs of the patient (Williams, 2018).

\section{Tools}

The Tools that was in used VA-ST is a tool designed to help patients with vision problems, both total and partial. It is based on a computer vision system that uses a device called Smart Specs. Thanks to it, 3D objects can be recognized and integrated into a real scene. This not only helps to improve the vision of many people, but also makes it easier for them to function better in unfamiliar environments (Ahmed et al., 2013). It is a medical simulation used by the company CAE Healthcare that makes use of Microsoft HoloLens. This tool applies mixed reality in medicine to interact with holograms superimposed on the real image. It is used primarily in anatomical medicine practices. It is an initiative carried out at the University of Valencia, whose objective is the treatment of children with autism. To do this, two patients are placed in different rooms, but with the possibility of communicating with each other. Both have to complete the same objective relying on the use of virtual reality, which contributes to solving communication problems through collaboration (Barré et al., 2019).

\section{Location of veins}

Augmented reality has helped to overcome one of the most painful situations that certain cancer and chronic patients have to suffer: the failed pricks when looking for veins to inoculate a treatment. AccuVein Company has designed a handheld scanner that is projected onto the skin to show the exact location of veins on the body of patients. According to its promoters, the level of success is 3.5 times higher than if the punctures are carried out without assistance (Asi and Williams, 2018). Also, it was, more entertaining and educational drug leaflet. Through augmented reality, pharmaceutical companies can forget the boring and long prospectuses and replace them with systems that graphically show how the drug works in the human body (Williams, 2018). Its 'Increased satiety' by the applications of augmented reality in healthcare also include the treatment of disorders.

An example is the 'Augmented Satiety' project. It is a method to combat obesity that they have developed at the University of Tokyo. Its operation is simple: the patient is given a piece of real food, which will be visualized through augmented reality. The virtual image will gradually increase in size, with the aim of tricking the brain into making the patient believe that the piece is larger than it is (Goh, 2016).

\section{AccuVein}

AccuVein is another example of augmented reality applied to today's medicine. Its function is to show an image of the vasculature superimposed on the skin, in order for healthcare professionals to easily find the veins when giving injections or performing blood tests. It also allows you to see their status and avoid injections into arterial bifurcations or valves.

\section{Google Glass to help new moms' breastfeed}

An innovation company called Small World, in Melbourne (Australia), developed for several weeks a test that featured Google Glass and the Australian Breastfeeding Association. Through these glasses, the association's experts were able to check the way in which new mothers or inexperienced mothers breastfed their babies to detect faults and offer them help. With this tool, mothers with difficulties were able to obtain external help at any time of the day and remotely. Despite the help that this trial was for all the participants, it was eventually parked. In ophthalmology, an application called Oculina, designed for people with loss of central vision, allows doctors to correct the functional vision of patients with severe age-related macular degeneration and create a virtual environment that allows them to read again.

\section{Comparison of Virtual and Augmented Reality}

Virtual and augmented reality also has applications in medicine, where it can improve the quality of tele-advice and telehealth. It can be used not only to improve the patient's contact with the doctor, but also to educate students (simulations of procedures or operations, distance learning and conversations with specialists from around the world) and patients (better understanding of the treatments and procedures waiting for them), or to conduct alternative 
therapies (currently used to treat long-term pain) The benefits of augmented reality in medicine are many and varied: It offers a wide variety of uses and applications: as we will see later in some examples, augmented reality is already applied in various fields of medicine, from diagnosis to surgery, through treatment of psychological problems. The Following Table 1 in below showing Difference very clearly:

Table 1: Comparison of VR and AR

\begin{tabular}{|l|l|}
\hline \multicolumn{1}{|c|}{ VIRTUAL REALITY } & \multicolumn{1}{c|}{ AUGMENTED REALITY } \\
\hline $\begin{array}{l}\text { Virtual reality is a technology } \\
\text { that generates a fully artificial } \\
\text { environment. }\end{array}$ & In Augmented reality, combines the real and the virtual world. \\
\hline $\begin{array}{l}\text { It includes image, sound, and sometimes } \\
\text { even touch and smell. }\end{array}$ & $\begin{array}{l}\text { 3D visualizations with which the user interacts are usually superimposed } \\
\text { on the image through glasses or devices (e.g., a telephone). }\end{array}$ \\
\hline It is often used, for example, in games. & $\begin{array}{l}\text { We can, for example, check whether the shoes we buy online will look good } \\
\text { on us and the cabinet will fit in the place where we would like to put it. }\end{array}$ \\
\hline
\end{tabular}

It facilitates a greater degree of interaction: doctors, doctors and patients can access 3D models that can be visualized and manipulated, thus improving the methods of diagnosis and treatment. Increase agility in administrative tasks: a clear example is Dignity Health, which allows doctors to make automatic transcripts of conversations with patients, which allows dividing by three the working time dedicated to administrative tasks. It can be integrated with many other applications in medicine, for example robotics. Reduces costs in the use of corpses or animals, especially when providing training. Avoid practices on real patients. Allows you to repeat training or diagnostic tasks as many times as you want. It contributes to the performance of much more reliable analyzes and to reduce the risk of operations and postoperative treatment. It can be combined with other immersive technologies, such as virtual reality in medicine.

\section{Medical Education: Worst Situation ANd SURGERY}

Patients' worst situations will continue to have a significant impact on surgical practice, and hospital guidance is urgently needed. Within medical schools, however, recommendations are also required for surgical postings. The surgical placement is a key aspect in fostering a student's enthusiasm in pursuing a surgical profession. Along with the already limited time available for surgical placements in the medical curriculum, may obstruct surgical education and, as a result, lower student interest in pursuing a surgical career. Studies (Ali et al., 2019; Mishra et al., 2018; Ali et al., 2014) show that a pleasant surgical rotation experience has a significant impact on future career choices. Indeed, surgical interest among UK medical students has been declining, and situational information may expedite this trend. As a result, much of the teaching has already moved to the internet. Surgery, on the other hand, is an art that can only be refined in the operating room. It is best to learn about the many instruments involved, the roles of the multidisciplinary team, and the procedures that clinicians take to maintain patient safety throughout the patient journey. Students will surely be at a disadvantage if they learn passively through texts. It may be time to change the way surgical education is delivered. Surgical training could be revolutionized with the use of telemedicine and augmented reality, where students can observe live proctoring by surgeons and engage remotely for a more immersive experience.

\section{CONCLUSION}

The article explained various applications and effectiveness of augmented reality in medical education. The growing awareness of the society makes it begin to focus on prevention and demand information about its current health condition. Augmented reality in medical education is much more important and offers many more possibilities than you might think. It is used, for example, in hospitals during operations, offices (including dentists - prosthetics, orthodontic appliances, prosthetic restorations), in the production of medical devices (e.g., hearing aids) or printing prostheses (including prostheses for children, where their rapid growth causes that they can quickly outgrow traditional dentures). Medical is working on a paradigm shift from reactive to proactive. We are building a world where we treat diseases before they become a health threat by providing medics with the time and technology they need to do so. Undoubtedly, augmented reality still has a long way to go in the medical field. Technology is advancing by leaps and bounds and surely new innovations will soon be seen that will revolutionize the health sector. All for the benefit of professionals and, of course, patients.

\section{REFERENCES}

Ahmed, A. A. A., Siddique, M. N., \& Masum, A. A. (2013). Online Library Adoption in Bangladesh: An Empirical Study. 2013 Fourth International Conference on e-Learning "Best Practices in Management, Design and Development of e-Courses: Standards of Excellence and Creativity", Manama, 216-219. https://doi.org/10.1109/ECONF.2013.30 
Ali, F. M., Sabir, M. M. H., Gohal, M. R. A., Ageeli, T. A. T., \& Mobarki, A. H. (2019). Accidental Swallowing of a Single Tooth Metal Crown of a Tooth in 38 Year Old Male Patient: A Case Report. Malaysian Journal of Medical and Biological Research, 6(1), 27-30. https://doi.org/10.18034/mjmbr.v6i1.465

Ali, Y. M., Sarwar, J. M., Sarker, M. C., Hossain, M. S., Kayes, M. N., Rahman, M. M., \& Hainz, H. (2014). Core Decompression by Laser Osteoperforation: A Preliminary Report of New and Minimally Invasive Modality for the Treatment of Avascular Necrosis of the Femoral Head.Malaysian Journal of Medical and Biological Research, 1(1), 9-17. https://doi.org/10.18034/mjmbr.v1i1.370

Asi, Y. M. and Williams, C. (2018). The role of digital health in making progress toward Sustainable Development Goal (SDG) 3 in conflict-affected populations. International Journal of Medical Informatics, 114(2018), 114-120, https://doi.org/10.1016/j.ijmedinf.2017.11.003

Barré, J., Michelet, D., Truchot, J., Jolivet, E., Recanzone, T., Stiti, S., Tesnière, A., \& Pourcher, G. (2019). Virtual Reality Single-Port Sleeve Gastrectomy Training Decreases Physical and Mental Workload in Novice Surgeons: An Exploratory Study. Obesity Surgery, 29, 1309-1316. https://doi.org/10.1007/s11695-018-03680-9

Barsom, E. Z., Graafland, M. \& Schijven, M. P. (2016). Systematic review on the effectiveness of augmented reality applications in medical training. Surg Endosc, 30, 4174-4183. https://doi.org/10.1007/s00464-016-4800-6

Barteit, S., Jahn, A., Banda, S. S., Bärnighausen, T., Bowa, A., Chileshe, G., Guzek, D., Jorge, M. M., Lüders, S., Malunga, G., Neuhann, F. (2019). E-Learning for Medical Education in Sub-Saharan Africa and LowResource Settings: Viewpoint. J Med Internet Res, 21(1), e12449. https://doi.org/10.2196/12449

Bleakley, A. (2013). Gender matters in medical education. Medical Education, 47(1), 59-70. https://doi.org/10.1111/j.1365-2923.2012.04351.x

Bretón-López, J., Quero, S., Botella, C., García-Palacios, A., Baños, R. M., Alcañiz, M. (2010). An Augmented Reality System Validation for the Treatment of Cockroach Phobia. Cyberpsychology, Behavior, and Social Networking, 13(6), 705-710. https://doi.org/10.1089/cyber.2009.0170

Chen, P., Liu, X., Cheng, W., Huang, R. (2017). A review of using Augmented Reality in Education from 2011 to 2016. In: Popescu E. et al. (eds) Innovations in Smart Learning. Lecture Notes in Educational Technology. Springer, Singapore. https://doi.org/10.1007/978-981-10-2419-1_2

Chimakurthi, V. N. S. S. (2017a). Cloud Security - A Semantic Approach in End to End Security Compliance. Engineering International, 5(2), 97-106. https://doi.org/10.18034/ei.v5i2.586

Chimakurthi, V. N. S. S. (2017b). Risks of Multi-Cloud Environment: Micro Services Based Architecture and Potential Challenges. ABC Research Alert, 5(3), United States. https://doi.org/10.18034/abcra.v5i3.590

Chimakurthi, V. N. S. S. (2018). Emerging of Virtual Reality (VR) Technology in Education and Training. Asian Journal of Humanity, Art and Literature, 5(2), 157-166. https://doi.org/10.18034/ajhal.v5i2.606

Goh, P. S. (2016). eLearning or technology enhanced learning in medical education-Hope, not hype, Medical Teacher, 38(9), 957-958. https://doi.org/10.3109/0142159X.2016.1147538

Hsieh, M. C. and Lee, J. J. (2018). Preliminary Study of VR and AR Applications in Medical and Healthcare Education. Journal of Nursing and Health Studies, 3(1.1), 1-5. https:/ / doi.org/10.21767/2574-2825.100030

Jensen, L., Konradsen, F. (2018). A review of the use of virtual reality head-mounted displays in education and training. Educ Inf Technol, 23, 1515-1529. https://doi.org/10.1007/s10639-017-9676-0

Mishra, S. R., Shobhana, S., Singh, S., Singh, R., \& Gaharwar, A. (2018). Morphometric and Topographic Study of Foramen Ovale in Indian Skulls. Malaysian Journal of Medical and Biological Research,5(2), 75-84. https://doi.org/10.18034/mjmbr.v5i2.455

Schijven, M. P., and Jakimowicz, J. J. (2005). Validation of virtual reality simulators: Key to the successful integration of a novel teaching technology into minimal access surgery. Minimally Invasive Therapy $\mathcal{E}$ Allied Technologies, 14(4-5), 244-246. https:/ / doi.org/10.1080/13645700500221881

Vera, A. M., Russo, M., Mohsin, A., Tsuda, S. (2014). Augmented reality telementoring (ART) platform: a randomized controlled trial to assess the efficacy of a new surgical education technology. Surg Endosc, 28, 3467-3472. https://doi.org/10.1007/s00464-014-3625-4

Williams, R. T. (2018). Confidence Interventions: Do They Work?. Asian Journal of Humanity, Art and Literature, 5(2), 123-134. https://doi.org/10.18034/ajhal.v5i2.536 
Williams, R. T., \& Scott, C. D. (2019). The Current State of Outdoor Learning in a U.K Secondary Setting: Exploring the Benefits, Drawbacks and Recommendations. ABC Journal of Advanced Research, 8(2), 109-122. https://doi.org/10.18034/abcjar.v8i2.537

$$
--0 \text {-- }
$$

How to cite this article

Chimakurthi, V. N. S. S. (2019). Efficacy of Augmented Reality in Medical Education. Malaysian Journal of Medical and Biological Research, 6(2), 135-142. https://doi.org/10.18034/mjmbr.v6i2.609 